cooler phases of less intensity are intercalated between Mindel 2 and Riss 1 and between Riss 2 and Würm 1. These have not yet been found outside central and south Germany. There are several cold phases older than Günz, but up to now they have only been proved for the Alps and a few river systems. They are older than the 'Diluvium', and possibly are contemporary with the earliest Pleistocene and Upper Pliocene of England.

In Milankovitch's radiation curve (all calculations are as from A.D. 1800) there are strong minima of solar radiation in a group of three at $23,000,72,000$ and 115,000 years; of two at 188,000 and 230,000 years; a long period without stronger minima of radiation stands between 240,000 and 430,000 years; there is another group of two minima at $\mathbf{4 3 5 , 0 0 0}$ and 476,000 years ; and an early group of two minima at 550,000 and 591,000 years. It can scarcely be coincidence that this arrangement is exactly the same as was found for the glacial phases of the Pleistocene. Not only are the threefold Würm and the doubled Riss, Mindel and Günz represented by strong minima of radiation, but also the great interglacial Mindel 2Riss 1 finds its equivalent in a period of nearly 200,000 years. The coincidence of so many details is almost amazing. An application of the curve solves many of the old problems of stratigraphy, as well as raises new.

The absolute chronology thus afforded also dates the remains of fossil man and his cultures more accurately than hitherto, but only provided their exact position in the stratigraphical succession has been determined. The most ancient find in Central Europe, Homo heidelbergensis from the Mauer sands, cannot be later than the interglacial between Günz 2 and Mindel 1. Many have correlated him with the Chellean, but it is not impossible to assign him a pre-Chellean culture with a place in the absolute scale of about 500,000 years. The Acheulean at Achenheim occurs in the loess of Riss 2 and falls within a glacial phase, though the evidence from Markleeberg suggests that it may extend further back, giving a possible antiquity of 183,000 years. The Mousterian stations Taubach and Ehringsdorf show that Neanderthal man was present in Germany in the last phase of the Interglacial Riss/Würm, and was still living there when the climate became colder with the advance of the Würm glaciation; while Wallertheim shows that he was there after the maximum of Würm 1. This dating indicates an antiquity covering the period from 140,000 to 105,000 . The Aurignacian, on the evidence from Linsenberg near Mayence, belongs to the beginning of Würm 2 and is dated from 95,000 to 69,000 and is followed by the Solutrean of Predmost, of which the precise age has still to be determined; but it is suggested on the strength of evidence from Kesslerloch that the Solutrean stands at 67,000. The Kesslerloch Magdalenian site was inhabited some time after the maximum of Würm 2, and most German Magdalenian is of about the same period; while in north Germany (Balver Höhle, Westphalia) the end of the Mag. dalenian is Würm 3. The whole Magdalenian is dated at 65,000 to 18,000 ; while the Mesolithic, after Würm 3, is assigned to 15,000 to 7,500 and the Neolithic in the post-glacial Atlantic phase dated 7,500 to 4,000 . (All dates are reckoned in years before A.D. 1800.)

In palæontology, the new chronology makes it possible to date the disappearance of ancient species and the appearance of new ones very exactly. We are enabled to study migrations and other alterations in the distribution of species with precision. For example, the hippopotamus, absent in Central Europe, except in the Rhine Valley, where it is typical of the early Pleistocene, persists into late Middle or even Upper Pleistocene in England. It can thus be shown to have survived in western Germany for a 100,000 years after it had disappeared from the rest of mid-Europe, while it survived in the oceanic climate of England for another 200,000 years longer.

The new chronology also enables us to estimate the time necessary for adaptation and other alterations of specific characters, of which the most intelligible instance is afforded by the elephants. Thus $E$. antiquus, a forest species, in 450,000 years developed very little; but in the same period $E$. primigenius shows a very marked specialisation owing to a new biotope. The Siberian mammoths may be about 15,000 years old. For the whole evolution of the mammoth the absolute chronology

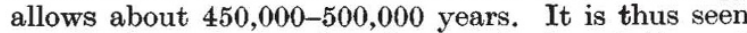
to afford a criterion for the speed of evolution, of which we know very little.

\title{
Coal and Gas in Great Britain
}

\begin{abstract}
A $\mathrm{T}$ the seventy-third annual meeting of the A Institution of Gas Engineers in London on May 26-29, the address of the president, Colonel W. Moncrieff Carr, referred to "perhaps the most serious problem in the history of the Industry" - the proposed coal selling scheme, under which not only the prices but also the choice of gas coal would be apparently at the discretion of the coal industry, which would thus acquire uncontrolled monopolistic power. It is feared that the coal industry's policy will be influenced by a desire voiced by its spokesmen and indicated by its commercial actions to discourage the replacement of raw coal by the products of coal carbonisation, even though this conduces to public amenity and hygiene and to private convenience.
\end{abstract}

Moreover, freedom of choice of raw material is vital to any manufacturing industry and especially where the raw material can be so variable as coal.

At the moment, the public gas supply is being concentrated into fewer and larger units by several paths-amalgamations of adjacent undertakings, by the establishment of 'gas grids' where local circumstances are favourable, and by the formation of holding companies controlling many but not neces. sarily adjoining undertakings. The merits and demerits of these activities are engaging much attention, to which a paper by Mr. F. C. Briggs on the Dudley Gas Amalgamation contributed. In south Yorkshire the coking industry produces an abundant supply of gas as a by-product which the 
gas grid controlled by the Sheffield Gas Co. has made available over a wide area and at prices lower than customary. The Rotherham Corporation has also taken advantage of the local supply of coke oven gas, and in order to encourage the use of gas instead of coal has instituted a two-part tariff with a very low consumption charge (10d. per $1,000 \mathrm{cub}$. $\mathrm{ft}$. of 500 B.T.U.). Mr. J. T. Haynes, formerly manager of the Rotherham undertaking, reported the success of the tariff, which has been adopted by consumers of all classes. The results show that, roughly speaking, $1,000 \mathrm{cub}$. ft. of gas does the work of I cwt. of domestic coal.

Mr. C. A. Masterman's paper on gas safety precautions contained much of interest. While considering steps to reduce the number of deaths from the use of gas, he indicated that the publicity given to such accidents creates a false impression of their frequency. Actually the fatality rate from coal gas in Great Britain is only a fraction of corresponding figures in other countries. The report of the Registrar General shows that coal gas accidents are only one fifth of those due to falling downstairs, while those due to products of combustion are insignificant.
Actually ten times as many people die as a result of falling out of bed as from the fumes of burning coal gas. Nevertheless, as a result of greater care in the service of gas appliances, the number of such accidents is diminishing, while the consumption of gas increases.

The paper by J. Jameson and Dr. J. G. King on the carbonisation of cannel at Edinburgh Gas Works gave interesting results which received an undesirable publicity in the daily Press. It was shown that a certain Scotch cannel yields on carbonisation not only a good yield of gas, but also of tar particularly suited for hydrogenation to give motor-spirit and a coke quite serviceable for domestic use. Unfortunately, it has been suggested that the carbonisation of cannel could be expanded almost to cover the nation's supply of liquid fuel. This is a myth which was exploded long ago, for example, during the War. Suitable cannels, as Messrs. Jameson and King indicated, are too irregular in supply and too variable in quality to form a basis of an industry of such magnitude. It is regrettable that the Press should be used to disseminate such perversions of the results of research.

\section{The Carnegie United Kingdom Trust}

$\mathrm{T}$ HE Carnegie United Kingdom Trust's twenty. second Annual Report couples with its description of the work of the year 1935 a general account of progress achieved during the past five years and an outline of its five-year plan for 1936-40. Some idea of the range of the Trustees' activities during the past quinquennium can be gathered from the following summary classification of grants: libraries, $£ 296,500$ (being 44 per cent of the total of all the grants); playing-fields and play-centres, $£ 125,000$; village halls, rural community councils, new estates community associations, youth hostels and other schemes for rural development and social service, $£ 162,600$; adult education (including museums), $£ 35,700$; music and drama, $£ 18,400$; miscellaneous, $£ 32,200$.

Two big changes of policy, one negative and one positive, differentiate the current from the past fiveyears' programme. Libraries have enjoyed the lion's share of the grants ever since the Trust's foundation, and three-fourths of this share has gone to county and municipal libraries. Last year, however, the Trust decided that for the future these institutions might safely be left to rely upon other resources. A similar decision was reached in regard to grants for special libraries, for newly formed rural community councils and for playing-fields : ". . . in each of these fields they [the Trustees] have helped to set up a standard of achievement which should enable those who are responsible locally to carry on the work and develop it adequately, and .... to give further help would stultify the pioneer principle which is at the root of the policy which their founder laid down".

It is in projects for land settlement that the Trustees have found an outlet for the funds thus set free. So long ago as 1933 , they commissioned Mr.
A. W. Menzies Kitchin, of the University of Cambridge Department of Agriculture, to investigate the potentialities of land settlement as an agency for social welfare, and ways and means for promoting it. His report, published last January, favours experiment along two lines: (1) co-operative smallholding schemes of 30-40 families, each holding being 3-10 acres of land; and (2) co-operative part-time subsistence holdings; and the Trustees have allocated $£ 150,000$ for schemes of these types. Already two schemes of type (1) are in being, both promoted by the Land Settlement Association, one at Potton (market garden holdings) on land given by $\mathrm{Mr}$. P. Malcolm Stewart, and one at Andover (poultry and pig holdings), and the Trustees have allotted $£ 10,000$ towards the capital cost of establishing three more such schemes (forty families each) in distressed areas in co-operation with county councils. Another $£ 10,000$ is allotted towards starting thirty part-time settlements of forty men each on the group-holding (quarter to half-acre) system-an experiment recently taken over from the Society of Friends.

Another entirely new allocation is one of $£ 30,000$ for encouraging amateur choral and orchestral societies and for holding short schools for conductors. As in the case of the land settlement schemes, this new venture has not been undertaken without prolonged inquiry and consideration. It will be under the direction of a joint committee of the Trustees and a national federation of amateur societies recently set up on the initiative of the Incorporated Society of Musicians.

The whole report is extremely interesting. The Trust's activities have a value over and above their directly beneficial results in that they are often conducted in such a way as to have permanent value as pieces of scientific research. 